\title{
PROFILE OF ELEMENTARY SCHOOL TEACHER IN CONCEPT UNDERSTANDING OF GEOMETRY
}

\author{
Samuel Igo Leton*, Kristoforus Djawa Djong, Irmina Veronika Uskono, Wilfridus Beda Nuba \\ Dosinaeng, Meryani Lakapu \\ Universitas Katolik Widya Mandira, Indonesia
}

\begin{tabular}{l} 
Article Info \\
\hline Article history: \\
Received Mar 3, 2020 \\
Revised Aug 1, 2020 \\
Accepted Aug 7, 2020 \\
\hline
\end{tabular}

\section{Keywords:}

Understanding of mathematical concepts,

Two-dimensional geometric shapes,

Arithmetic skills,

Elementary school teachers

\begin{abstract}
Students need teachers with a deep understanding of mathematical concepts to improve their mathematical knowledge and achievement. The observation results of several elementary school teachers showed that they still have a lack of understanding of the geometry concepts. This research is an exploratory study with a qualitative approach that aims to describe the performance of elementary school teachers in understanding the concepts of triangles and squares. The participants in this study were elementary school teachers across Soe City District. A description test deals with the geometry concept of twodimensional shapes that were implemented to determine the most appropriate teachers to participate in the study. Thirty-three teachers were then selected based on this preliminary test results. In-depth interviews were also conducted with the participants. The data analysis showed that the participants had a lack of understanding of the concept of two-dimensional shapes and necessary arithmetic skills. Moreover, the data suggested that the participants held various perceptions regarding their understanding of certain concepts based on their experience in teaching the mathematical concept. Based on these results, some programs are recommended to improve professionalism and pedagogical competencies, such as a refresher training program for basic mathematical material and training in teaching aids used. These programs are expected to help prepare elementary school teachers in teaching mathematics.
\end{abstract}

Copyright $\left({ }_{0} 2020\right.$ IKIP Siliwangi. All rights reserved.

\section{Corresponding Author:}

Samuel Igo Leton,

Department of Mathematics Education,

Universitas Katolik Widya Mandira

JL Jend Ahmad Yani No.50-52, Kupang, East Nusa Tenggara 85225, Indonesia

Email: letonsamuel@unwira.ac.id

\section{How to Cite:}

Leton, S. I., Djong, K. D., Uskono, I. V., Dosinaeng, W. B. N., \& Lakapu, M. (2020). Profile of elementary school teacher in concept understanding of geometry. Infinity, 9(2), 133-146.

\section{INTRODUCTION}

Mathematical understanding is an essential component of the mathematical skills needed for anyone to learn mathematics successfully (Stylianides \& Stylianides, 2007). One of the expertise expected to be achieved when studying mathematics is understanding mathematical concepts (Mwakapenda, 2004). This is observed through the ability to: (1) convey their understanding of the learned concepts; (2) explain the interrelationships between concepts; and (3) apply the concepts flexibly, accurately, efficiently, and precisely in problem-solving (Depdiknas, 2003). Understanding mathematical conceptsalso refers to 
the ability to: (1) explain the concept; (2) implementthe concepts in various situations; and (3) develop some consequences of the existence of a concept that can explain the interrelationships between concepts and its application or algorithms flexibly, accurately, efficiently, and precisely in problem-solving (Duffin \& Simpson, 2000).

One's mathematical ability is greatly influenced by his understanding of mathematical concepts and principles learned. The ability to understand mathematical concepts for elementary school teachers has received much attention in the last few decades. Understanding mathematical content refers to the basic mathematical knowledge possessed by these teachers. Mastery of mathematical concepts is essential because it facilitates teachers in teaching mathematics so that students can easily understand it. Mastery of mathematical concepts is a necessary construct that can support or hinder student learning progress (Philipp et al., 2007). Lack of mastery of mathematical concepts possessed by elementary school teachers can lead to mathematics misconceptions among students as well asno improvement or changes in learning (Thames \& Ball, 2010). Thus, a good mastery of mathematical concepts can assist the development of mathematical connection capabilities between various ideas, help to understand how mathematical ideas are interrelated to one another so that a comprehensive understanding is possible, and the ability to use mathematics in contexts outside mathematics (Korn, 2014).Therefore, the deeper the mathematical knowledge possessed by teachers, the better it is to communicate mathematical concepts, models, and representations with students (Philipp et al., 2007).

Mastery of mathematical concepts greatly affect student learning outcomes (Sowder, 2007). To improve mathematical knowledge and achievement, students need teachers with deep mathematical knowledge. Grover and Cannor (2000) suggests that content knowledge is a key factor of effective teaching. They found that teachers not only understood mathematics, but also concepts that would support effective teaching (Grover \& Connor, 2000). The observation data on how elementary school teachers teach mathematics suggests that there is still plenty of teachers who do not understand the concept of the area of a rectangular area very well. These teachers only memorize the formula for the area of a rectangular area that is length $\times$ width without knowing the concept of the area. Even when they were asked whether the area of a rectangle be written as width $\times$ length, they firmly believe that it is incorrect because the correct formula is length $\times$ width and not the other way around. It seems they were trapped in believing that a concept is considered correct because it is widely accepted as a habit instead of according to the mathematical concept. They tend to hold the belief that the mathematical concepts possessed for teaching mathematics are based on their experience in mathematics classes that have been built up from time to time and that are considered valid (Ball, Lubienski \& Mewborn, 2001). They accept more of what they read or learn as truth without daring to question the reason behind the formula. This fact shows that not all elementary school teachers master the basic mathematical concepts correctly. This can be detrimental to the students they teach. The results of UASBN data analysis of 2017/2018 and 2018/2019 for mathematics of 504 elementary schools in the South-Central Timor regency, were obtained an average of 58.19 and 52.70 with the lowest scores of 13.37 and 20.83. Concerning the UASBN results and observational data, we believe that there is a need to enhance teachers' professionalism and pedagogical competencies in the form of training/course. This should be done by first mapping out the mathematical concepts understood by the teachers. This mathematical training/course needs to be related to the development of basic mathematical concepts and pedagogy (Thames \& Ball, 2010).

In this paper, we examine the application of basic mathematical concepts by elementary school teachers regarding two-dimensional shapes. To our knowledge, there are no in-depth studies to explore the mastery of mathematical concepts by elementary 
schoolteachers regarding two-dimensional shapes. This study seeks to identify findings related to the mastery of mathematical concepts possessed by elementary school teachers for professionalism and pedagogical competencies improvement program to meet the needs of developing mathematics in elementary schools. Therefore, this study focuses on addressing the following questions: What are the participants' understanding of the concept of the area of a triangle, the area of a rectangle, and how they teach the concept; also, basic arithmetic skills related to solving given problems.

\section{METHOD}

This research is an exploratory study with a qualitative approach that aims to obtain a depiction of the performance of elementary school teachers in understanding the concept of geometry. The research focuses on understanding the geometrical concepts held by elementary school teachers. Exploration was carried out in detail on the capabilities of each teacher in answering questions related to the concept of area which consists of the area of a rectangle and the area of a triangle; how they teach the concept; also, basic arithmetic skills related to solving given problems. The subjects in this study were elementary school teachers across Soe City District which were purposively selected. The participants were selected through a test. The test consists of 18 items related to the geometry concept of twodimensional shapes. The test results were then analyzed and grouped into several groups of answers as follows (Table 1).

Table 1. The rubric scoring for mathematical representations

\begin{tabular}{|c|c|c|}
\hline $\begin{array}{l}\text { Teacher Answer } \\
\text { Group }\end{array}$ & Code & Description \\
\hline \multirow[t]{6}{*}{$\begin{array}{l}\text { Based on the } \\
\text { definition of area }\end{array}$} & L1 & $\begin{array}{l}\text { The area of a two-dimensional shape is the number of } \\
\text { square units that cover the entire surface of the two- } \\
\text { dimensional shape }\end{array}$ \\
\hline & $\mathrm{L} 2$ & $\begin{array}{l}\text { The area of a two-dimensional shape is related to the } \\
\text { length, width, (and height) of the two-dimensional } \\
\text { shape itself. }\end{array}$ \\
\hline & L3 & $\begin{array}{l}\text { The size of an area is the number of sides of the two- } \\
\text { dimensional shape itself. }\end{array}$ \\
\hline & L4 & $\begin{array}{l}\text { The area of a two-dimensional shape is related to ribs } \\
\text { and lines }\end{array}$ \\
\hline & L5 & Unclear answer \\
\hline & L6 & No answer is given \\
\hline \multirow{5}{*}{$\begin{array}{l}\text { Based on the } \\
\text { definition of square } \\
\text { and rectangle }\end{array}$} & $\mathrm{P} 1$ & $\begin{array}{l}\text { Squares and rectangles are explained based on the } \\
\text { characteristics of their shapes }\end{array}$ \\
\hline & $\mathrm{P} 2$ & $\begin{array}{l}\text { Squares and rectangles are explained based on their } \\
\text { perimeter }\end{array}$ \\
\hline & P3 & $\begin{array}{l}\text { Squares and rectangles are explained based on the size } \\
\text { of all of their four sides }\end{array}$ \\
\hline & $\mathrm{P} 4$ & No clear answer is given \\
\hline & LP1 & $A=l \times w$ as stated by the experts \\
\hline
\end{tabular}




\begin{tabular}{lll}
\hline \multicolumn{1}{c}{$\begin{array}{c}\text { Teacher Answer } \\
\text { Group }\end{array}$} & Code & \multicolumn{1}{c}{ Description } \\
\hline $\begin{array}{l}\text { Based on the area of a } \\
\text { square }\end{array}$ & LP2 & $\begin{array}{l}A=l \times w \text { because it is the formula they got since they } \\
\text { were in school }\end{array}$ \\
\cline { 2 - 3 } & LP3 & $A=l \times w$ because the length must be written down first \\
\cline { 2 - 3 } & LP4 & $\begin{array}{l}\text { Both are correct because they correspond to the } \\
\text { commutative nature of multiplication }\end{array}$ \\
\cline { 2 - 3 } & LP5 & No clear answer is given \\
\hline $\begin{array}{l}\text { Based on the } \\
\text { understanding of the } \\
\text { rectangular area } \\
\text { formula }\end{array}$ & LP1 & $A=l \times w$ as stated by the experts \\
\cline { 2 - 3 } & KP2 & $\begin{array}{l}\text { Answer that } l \times p \text { is the formula to calculate the area of } \\
\text { a rectangle }\end{array}$ \\
\hline $\begin{array}{l}\text { Based on the } \\
\text { understanding of the } \\
\text { relationship between } \\
\text { square and rectangle }\end{array}$ & PP1 & States that square is considered as a rectangle \\
\cline { 2 - 3 } & States that square is not considered as a rectangle \\
\hline
\end{tabular}

Based on the analysis of the test results, 33 teachers who were considered able to contribute to providing data to attain the research objectives were then selected as the participants. In-depth interviews were also conducted to ascertain their understanding of the concept of area, how they teach these concepts, and basic arithmetic skills related to solving the given problems. Since the researchers acted as the main instrument, the questions presented during interviews were open-ended; thus, the questions can be improvised according to research needs.

The analytical model used in this study is an analysis based on the ideas generated from the teachers that refer to the correct mathematical concepts or definitions that have been prepared previously. Some recommendations then are provided based on the results in regard to the competency development program for elementary school teachers in supporting better mathematics learning.

\section{RESULTS AND DISCUSSION}

\subsection{Results}

Data analysis in this study consists of the analysis of the data collected from the test result and semi-structured interviews of 33 participant teachers on their understanding of the concept of a two-dimensional shape. This is divided into three parts: the concept of the twodimensional area consisting of the area of a rectangle and the area of a triangle; how they teach the concepts; also, basic arithmetic skills related to solving given problems.

In connection with understanding the concept of two-dimensional area, the teachers were asked to explain what they understand about the two-dimensional area. The results then are grouped in Table 2 as follows. 
Table 2. Teacher answer group based on the definition of area

\begin{tabular}{ccc}
\hline Group & Number of teachers & Percentage \\
\hline L1 & 3 & $9 \%$ \\
L2 & 20 & $61 \%$ \\
L3 & 2 & $6 \%$ \\
L4 & 3 & $9 \%$ \\
L5 & 4 & $12 \%$ \\
L6 & 1 & $3 \%$ \\
\hline
\end{tabular}

Group L1 was a group that was able to precisely explain the concept of twodimensional area asthe number of square units that cover the entire surface of a twodimensional shape. $9 \%$ of the total number of the participant teachers were in this group. Some teachers in this group used pictures to explain the answers, as shown in Figure 1.

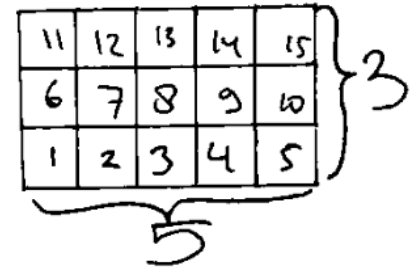

Figure 1. A teacher's understanding of the concept of area in group L1

Based on Figure 1, one of the teachers from group L1 explained that the twodimensional area could be obtained by calculating the number of square units that can be formed as seen in Figure 1. Thus, the area of a rectangle with $5 \mathrm{~cm}$ in length and a width of $3 \mathrm{~cm}$ can be calculated using the concept. However, the participant teachers appeared to apply this concept only when dealing with two-dimensional shapes of square and rectangle. When they were asked about the area of other types of two-dimensional shapes, they were not able to explain the related mathematical concept.

Group L2 wasthe group that explained the area of two-dimensional shapes using the length, width, (and height) of the shapes as mentioned earlier. There were $61 \%$ of the total number of participant teachers in this group. The teachers in Group L2 explained area as a measure of the area obtained by calculating the length and width or the length (base) and height of the two-dimensional shape and operate it using specific predetermined formulas. They were able to quickly determine the area of a rectangle that was $5 \mathrm{~cm}$ long and $3 \mathrm{~cm}$ wide but failed to explain why the answer was correct. The mathematical concept of area is understood procedurally, which is to remember a formula that can be used to calculate the area of the two-dimensional shape and how to apply it without understanding why the formula is correct (Figure 2).

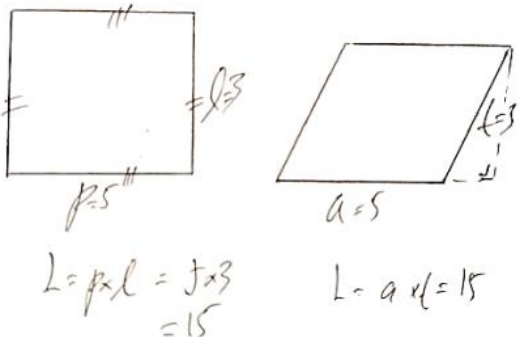

Figure 2. A teacher's understanding of the concept of area in group L2 
Group L3 consisted of teachers who explained the concept of the area of twodimensional shapes based on the number of sides of the shape. There was $6 \%$ of the teachers included in this group. Using a rectangle, the teacher in Group L3 explained the area of the two-dimensional shape as the sum of the four sides of the rectangle. Based on this understanding, the area of a rectangle measuring $5 \mathrm{~cm}$ long and $3 \mathrm{~cm}$ wide was calculated by adding up the two lengths and widths equal to $16 \mathrm{~cm} 2$. However, they were confused when they realized that the results were different if the calculation was done using the rectangular area formula. From the explanation given, it wasclear that the teachers in the L3 group were unable to conceptually distinguish the area from the perimeter of a twodimensional (rectangular) shape. Like Group L2, they remembered the formula but did not understand why itwas conceptually correct.

Group L4 was a group of teachers who explained the concept of a two-dimensional shape area related to ribs and lines. $9 \%$ of the total participant teachers fell under this category. The teachers in this group understood the area of two-dimensional shape as the area formed by the intersection of line segments. They argued that when the line segments intersect, a space formed in the middle of the intersection is a two-dimensional area. Based on the understanding that a line is a set of points, a two-dimensional shape such as a rectangle is considered as a set of all points from four lines facing each other. While the area of a twodimensional shape, according to this group, is the area bounded by these lines (Figure 3).

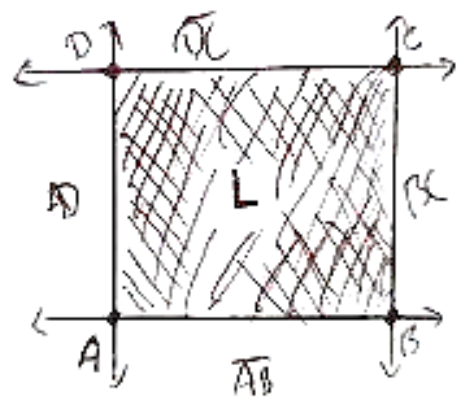

Figure 3. A teacher's understanding of the concept of area in group L4

Group L5 was a group of teachers who did not have a clear answer to the question. The teachers who were classified in this group were those who did not provide a clear response. $12 \%$ of the total participant teachers were included in this group. The responses collected from this group, including: (1) To obtain the area of a two-dimensional shape we must measure and calculate how much volume is in the two-dimensional shape; (2) The area of a two-dimensional shape is the size of an object known by tracing its full shape; (3) The area of a two-dimensional shape is a shape withthe sides unit of lengths; (4) The area of a two-dimensional shape is a shape with the same length and is parallel.

\section{Elementary School Teachers' Understanding of Square and Rectangular Concepts}

The first analysis is carried out on the concepts of square and rectangle. The teachers' answers are grouped in Table 3. 
Table 3. Teacher answer group based on definition of square and rectangle

\begin{tabular}{ccc}
\hline Group & Number ofteachers & Percentage \\
\hline P1 & 17 & $51.5 \%$ \\
P2 & 3 & $9.1 \%$ \\
P3 & 11 & $33.3 \%$ \\
P4 & 2 & $6.1 \%$ \\
\hline
\end{tabular}

As presented in Table 3, Group P1 was the group with the highest percentage (51.5\%). They explained the concept of square and rectangle based on the characteristics of these two shapes. A rectangle was understood as a two-dimensional shape which has two pairs of sides of equal length, all four angles are right-angled, and has two diagonals of the same length. Meanwhile, a square was understood as a two-dimensional shape formed by four equal lengths and four right angles. They were able to name the characteristics of twodimensional shapes precisely but did not correctly understand the concept of the length and width of the rectangle. The results of our interviews with the teachers in this group showed that they generally understood length as the longer side, and width as the shorter side. We argue that there was a misunderstanding that length is the longer side, and the width is the shorter side (Figure 4).

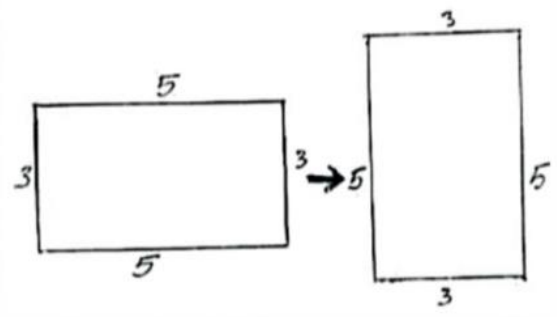

Figure 4. Length and width of a rectangle sized when rotated

Group P2 wasthe group that explains the meaning of square and rectangle using the concept of perimeter. They described a rectangle as a two-dimensional shape that has a length and width, with a perimeter of two times the length and twice its width, while a square is a two-dimensional shape with the same length and width (sides) and the perimeter is four times the length of the sides. The participant teachers then were shown a picture of parallelogram whereits four sides have the same length and asking them to determine the type of the shape. They said that it was a parallelogram and they improved their descriptionof the square by adding that on a square the angle was $90^{\circ}$. The next image to be determined was a square that had been rotated $45^{\circ}$. Almost all teachers in this group classified the picture as a rhombus and not square because they thought the shape was different from the shape of a typical square. We argue that the participant teachers generally did not have a sound understanding of the relationship between a square and a rhombus that the two is not necessarily a square.

Group P3 wasthe group that stated that the meaning of squares and rectangles are explained based on the size of all of their four sides (33.3\%). They described rectangles as two-dimensional shapes that have long sides and wide sides of different sizes; the longer side is called the long side, and the shorter side is called the wide side, and the square is a two-dimensional shape that has four same and congruent lines (sides). During the interview, most of them explained that what was meant by same was that the four sides were both in the form of a straight line and the four sides have the same length. To further explore their understanding of the concept of squares and rectangles, two images were presented. The first was a parallelogram that had the same length on all four sides; the second imagewas a 
rectangle that had the same side length as the parallelogram side. The participants were asked to determine whether the two shapes were congruent. Based on their understanding of the congruent concept, they generally classified the two structures as two congruent shapes. When they were asked to elaborate their answer on howthe shapeswere congruent, they said because the two shapes have the same side length. We argue that the teachers in this group did not understand well the concept of the congruency of two two-dimensional shapes (Figure 5).

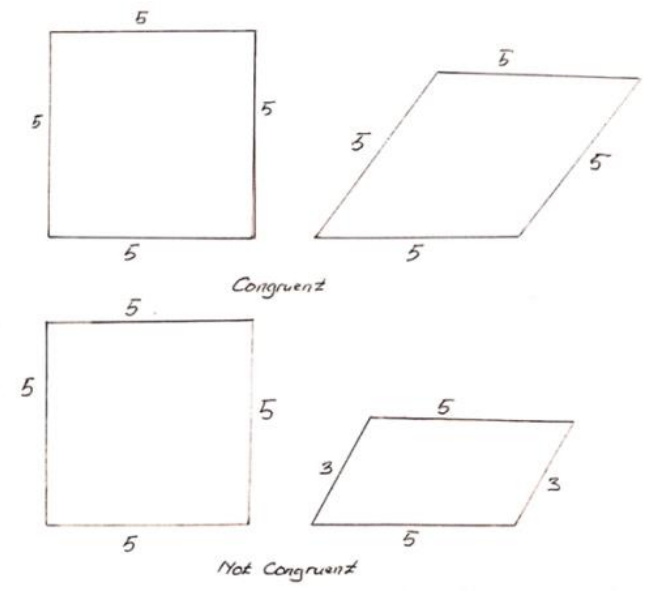

Figure 5. A teacher's answer when classifying the congruency of two two-dimensional shapes

Group P4 wasa group of teachers thatprovided answers that were not following mathematical concepts. In general, they explained the concept of squares and rectangles as a two-dimensional shape that has angles, angles, sides, and segments. Some believed that a rectangle was a two-dimensional box-like shape, while a square was a two-dimensional shape that has the same length and sides. The researchers agreed with this answer; the teachers in this group knew which pictures or objects are square or rectangle. They were also able to mention the elements of a square or a rectangle. This suggested that this group had a lack of understanding in regard to the concepts of two-dimensional shapes. Their understanding was limited to images, drawings, and concrete objects in the shape of a square and rectangle. We argue that, in general, they did not have a strong understanding of the mathematical concepts of squares and rectangles both their definitions and properties.

\section{Elementary School Teachers' Understanding of the Concept of Rectangular Area}

The subsequent analysis focuseson how teachers understand the concept of a rectangular area. The teachers were asked to determine which formula is the correct one to calculatea rectangular area: $l \times w$ or $w \times l$. The responses are grouped in Table 4 .

Table 4. Teacher answer group about the area of a rectangle

\begin{tabular}{ccc}
\hline Group & Number of teachers & Percentage \\
\hline LP1 & 18 & $54 \%$ \\
LP2 & 4 & $13 \%$ \\
LP3 & 2 & $6 \%$ \\
LP4 & 8 & $24 \%$ \\
LP5 & 1 & $3 \%$ \\
\hline
\end{tabular}


Group LP1 was the group of teachers that stated $A=l \times w$ is the correct formula to calculate the area of a rectangle instead of $A=w \times l$. They argued that this was following the existing formula. 54\% of the total teachers were in this group. One of the teachers in this group argued: "... the correct formula is $A=l \times w$ because the experts have determined it since long time ago and no one can change it". This shows that this group had a lack of understanding of the rectanglearea, whichwas still limited to memorizing the formula without understanding why the formula is correct or where it came from. The second group (LP2) were the teachers who believed that $A=l \times w$ is the correct formula to calculate the area of a rectangle because it is the formula they learnt since they were in school. There were $13 \%$ of teachers who were included in this group. Similar to LP1, LP2 group teachers also did not understand the concept of the rectangular area. Their understanding was still limited so that they were not able to give a proper reason for the rectangular area formula.

Group LP3 consisted of teachers who believed that $A=l \times w$ is the correct formula to calculate the area of a rectangle because they thought the length must be written down first. There are $6 \%$ of teachers who were included in this group. They assumed that the correct formula is $A=l \times w$ because this is the order of how it is written on the school textbooks. When calculating the area of a rectangle, the length is written down before the width. Group LP4 consistedof the teachers who stated that the rectangular area formula is $A$ $=l \times w=w \times l$ because it is based on the commutative nature of integer multiplication where $a \times b=b \times a .24 \%$ of teachers were included in this group. Group LP5 consisted of teachers who did not provide clear answers. One of the teachers explained that the area of the rectangle is $A=1 \times w$ because a rectangle has two pairs of ribs of the same length and parallel also four right angles. This particular teacherdid not have a well understanding of the concept of the two-dimensional area; thus, he only mentioned the characteristics of rectangles according to his understanding to answer the questions given.

Concerning the answers above, we argue that in general, the participant teachers did not understand the concept of the area of a two-dimensional shape, causing them to be shackled by a habit that has been used and considered correctsince long ago which is $A=l$ $\mathrm{x} w$ and not the other way around. This was evidenced by a large number of participants who cannot properly interpret the questions given as follows: $\mathrm{An} A B C D$ rectangle with $\mathrm{AB}=5$ $\mathrm{cm}$ and $\mathrm{BC} 10 \mathrm{~cm}$. The area of the rectangle $=$ length $\times$ width $=5 \mathrm{~cm} \times 10 \mathrm{~cm}=50 \mathrm{~cm}^{2} . W e$ classified the answers from the teachers in Table 5.

Table 5. Teacher answer group

\begin{tabular}{ccc}
\hline Group & Number of teachers & Percentage \\
\hline KP1 & 5 & $15 \%$ \\
KP2 & 28 & $85 \%$ \\
\hline
\end{tabular}

Group KP1 was a group of teachers who stated that the solutionwas correct. As can be observed in Table 5, there were five out of 33 teachers who agreed that the statement was correct. These five teachers were interviewed to explore their arguments regarding the statements further. Four of these teachers argued that the solution wascorrect because it was following the formula of length $\mathrm{x}$ wide. Their reasoning was correct but only limited to known formulas, without defining in more detail. Moreover, one of the teachers argued that the statement was correct since $\angle \mathrm{AB}$ is the length and $\angle \mathrm{BC}$ is the wide. This confirms that the teacher cannot distinguish an angle from a length of a line; hence he assumed that the angle and length of a line were the same things. 
Group KP2 consisted of teachers who believed that the solution was incorrect. The interview results showed that most of them had similar reasoning towards the statement that the length is $10 \mathrm{~cm}$ and the width is $5 \mathrm{~cm}$. Therefore, the rectangle area $=$ length $\times$ width $=$ $10 \mathrm{~cm} \times 5 \mathrm{~cm}=50 \mathrm{~cm}^{2}$. This suggested that the teacher understood the concept of the rectangular area is length $\times$ width. They understand that the length of the rectangle is longer than the width. This concept has been accepted for long and considered correct. It has been considered correct not because it follows a mathematical concept where the size of the sides (length and width) on a rectangle only states a dimension of a two-dimensional shape but as a custom.

\section{Elementary School Teachers' Understanding on Whether a Square can be categorized as a Rectangle?}

The analysis of teachers responses on "Whether a square can be categorized as a rectangle?" can be observed in Table 6.

Table 6. Teacher answer group

\begin{tabular}{ccc}
\hline Group & Number of teachers & Percentage \\
\hline PP1 & 6 & $18 \%$ \\
PP2 & 27 & $82 \%$ \\
\hline
\end{tabular}

Group PP1 was a group of teachers who correctly answered that a square can be categorized as a rectangle (18\% or six out of 33 teachers). These six teachers provided different reasons for their answers in the follow-up interview. Some of them believed "... because a square is a rectangular two-dimensional shape that has four parallel and equal sides and four right angles ...". Some teachers provided incomplete reasons, “ ... because they have four sides." In addition, some teachers gave an inconsistent argument as well, saying that a square is a rectangle while stating that a square has four different sides of length and width.

Group PP2 was a group of teachers who stated that a square could not be categorized as a rectangle. 27 out of 33 teachers who did not approve the statement provided several different arguments in the follow-up interview. For one, a square cannot be categorized as a rectangle because the formula to calculate the perimeter of a square is $4 \mathrm{~s}$. While to calculate the perimeter of a rectangle we use $2 \times 1$ and $2 \times \mathrm{w}$; some teachers also suggested that the formula for the area of a rectangle is different from that of a square as in Asquare $=\mathrm{s} x \mathrm{~s}$ while ARectangle $=1 \mathrm{x}$ w. Some teachers also provided arguments based on differences in the size of the four sides. It appeared that their answers were based on the differences in area, perimeter and side size of the two shapes. The participants did not understand that the perimeter concepts of the two shapes are the same; the only difference is the symbols used. None of the participants provided any explanation based on the properties possessed by a square and a rectangle. They did not know that both a square and a rectangle share the same characteristics; thus, a square can be categorized as a rectangle. These findings confirm that the participants did not understand well the properties of a square and a rectangle, hence they cannot provide arguments that are considered as mathematically correct regarding the relationship between a square and a rectangle. 


\section{Teachers' Understanding of the Concept of Area of a Triangle}

The results of the analysis of the questions related to their understanding of the concept of the area of the triangle area, obtained information that in general they provide answers based on the formula to calculate the area of a triangle that has been widely accepted, to find the area of a triangle we must multiply the base of the triangle by its height. During the follow-up interview, all of the participants were able to correctly mention the formula to calculate the area of a triangle which is $A=\frac{1}{2} b \times h$. To further explore their understanding, the participants were then asked why the formula is as stated above. Several answers were given included this formula is part of a rectangle; this formula $=$ the area of the rectangle, divided by two; and this formula is a derivative formula of a rectangle. These answers were rooted from the same idea: a rectangle that is divided in two using one of its diagonals create two triangles; hence the area of a triangle is equal to half of the area of a rectangle. Next, the participants were asked to explain how to teach the concept of the area of a triangle. Most of the participant teachers believed that it is sufficient to teach the concept by making the pupils memorize the formula. They argued that memorizing formulas does not cause any problem because students memorize them in multiplication operations of the numbers. We argued that this is a misperception on the teachers' side in regard to the understanding of mathematical concepts, where understanding the concept is critical compared to only memorizing formulas. This may occur due to a lack of understanding of the triangle area from the teacher side. Thus, this concept is difficult to be correctly taught to the students. This is evidenced by a large number of participants who cannot solve the problems given below (Figure 6).
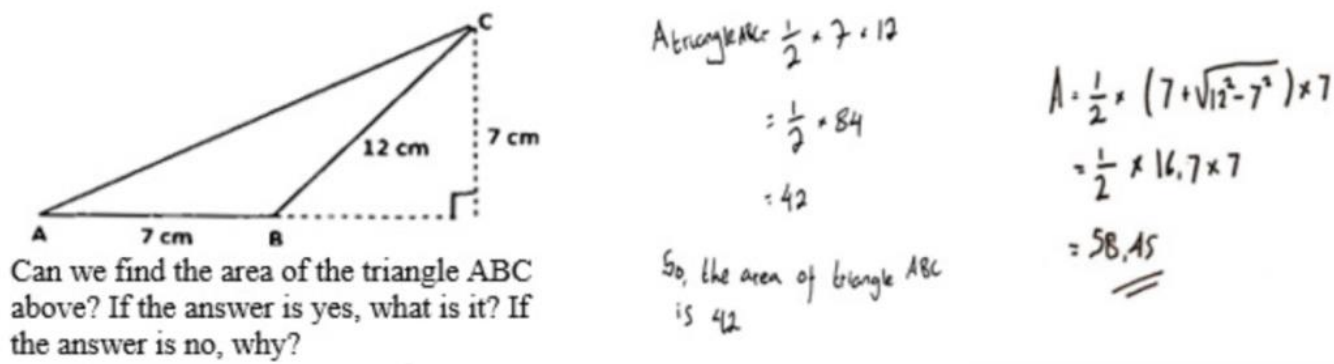

Figure 6. Samples of teacher answers related to the area of a triangle

From the sample answers in Figure 6, it appeared that the participants could not solve the problem correctly. The results of the interview data analysis showed that in general, it was difficult for the participants to determine the height of an obtuse triangle. The difficulty was caused by the lack of understanding of the concept of height in a triangle. They were accustomed to giving questions related to the image of an acute triangle or a picture of a right triangle so that when solving problems using an image of an obtuse triangle, they generally cannot solve the problem correctly.

\subsection{Discussion}

The results of the data analysis from the test and the semi-structured interview provide a depiction of the performance of elementary school teachers in understanding the concept of the geometry of the two-dimensional shape. In general, the findings of this study indicate the low mastery of the concept of two-dimensional shapes such as square, rectangle, and triangle as well as the low basic numeracy skills possessed by elementary school teachers in solving mathematical problems. The participants argue that heavy teaching workload is 
the cause of their lack of mastery. When a particular concept is not well mastered, the teacher tends to skip the lesson. They have varying degrees of mathematical proficiency and in many cases, maybe lacking knowledge bases (Cai \& Wang, 2010; Vistro-yu, 2013). Based on the findings, the researchers would like to propose some recommendations to be considered in order to establish a program to enhance professionalism and pedagogical competence for elementary school teachers. The researchers believe that there is a need for a refresher training program in regard to mathematical concepts. The elementary school teachers lack an understanding of the concept of two-dimensional shapes needs to get attention. Teachers lack understanding can severely affect teaching and learning in the classroom since they are the guide for students in learning. They must have sufficient mathematical knowledge to teach mathematics (Kasoka, Jakobsen \& Kazima, 2017). The more in-depth the mathematical knowledge of a teacher, the better they can communicate mathematical concepts, models, and representations to their students (Philipp et al., 2007).

Based on the results of this study, the researchers suggest that teachers need to deepen their understanding of mathematical concepts through competency improvement programs, especially in regard to their professionalism. Professionalism in this sense refers to the ability to master the mathematical content knowledge, which is the foundation of mathematics teaching that must be possessed by teachers (Ball, Thames \& Phelps, 2008). The knowledge about the concept of a two-dimensional shape needs to be improved from only memorizing formulas to understanding the formulas and the rules or to know the characteristics of a twodimensional shape. Teachers with insufficient content knowledge will find it challenging to explain mathematical concepts, provide models, and build relationships between concepts (Reid \& Reid, 2017) and difficult in developing HOTS-oriented problems (Dosinaeng, Leton \& Lakapu, 2019). Therefore, there is a need for government-facilitated programs provided by the education office or by the teacher associations such as Subject Teacher Group or Teacher Working Group to improve their mathematical knowledge. Through this process, groups of teachers in the association can be actively involved and work together to strengthen their mathematics teaching skills and thus positively affect students' mathematics achievement (Reid, 2013). The training that teachers join in improving their competence, as well as their educational background, have a more significant influence on teacher professionalism than their teaching experience or the length of teaching time (Harisman, Kusumah, Kusnandi \& Noto, 2019). These training programs are expected to help prepare teachers to teach mathematics to elementary school students.

\section{CONCLUSION}

The mastery of basic mathematical concepts is the foundation of knowledge that elementary school teachers need to have. The findings of this study suggest that the mastery of the concept of two-dimensional shapes and the teachers' experience in teaching mathematics at the elementary school level is still very low and limited to what is provided in the textbook. Apart from the low level of basic arithmetic skills and their experience in teaching mathematics, elementary school teachers need to take refresher training programs to improve their professional and pedagogic competencies. This recommendation stems from the fact that the teachers generally do not master the basic concept of two-dimensional shapes even though they are teaching at the elementary school level which supposed to be the ones who are responsible for building the mathematical foundation for students. The researchers believe that when these refresher training programs have been implemented, at minimum the issues related to the low mastery of the mathematical concepts can be 
overcome and ultimately can improve the quality of mathematics learning in the elementary school level.

\section{REFERENCES}

Ball, D. L., Lubienski, S. T., \& Mewborn, D. S. (2001). Research on teaching mathematics: The unsolved problem of teachers' mathematical knowledge. Handbook of research on teaching, 4, 433-456.

Ball, D. L., Thames, M. H., \& Phelps, G. (2008). Content knowledge for teaching: What makes it special. Journal of teacher education, 59(5), 389-407. https://doi.org/10.1177/0022487108324554

Cai, J., \& Wang, T. (2010). Conceptions of effective mathematics teaching within a cultural context: Perspectives of teachers from China and the United States. Journal of Mathematics Teacher Education, 13(3), 265-287. https://doi.org/10.1007/s10857009-91

Depdiknas. (2003). Pedoman Khusus Pengembangan Sistem Penilaian Berbasis Kompetensi SMP. Jakarta: Depdiknas.

Dosinaeng, W. B. N., Leton, S. I., \& Lakapu, M. (2019). Kemampuan Mahasiswa dalam Menyelesaikan Masalah Matematis Berorientasi HOTS. JNPM (Jurnal Nasional Pendidikan Matematika), 3(2), 250-264. https://doi.org/10.33603/jnpm.v3i2.2197

Duffin, J. M., \& Simpson, A. P. (2000). A Search for Understanding. Journal of Mathematical Behavior, 18(4), 415-427. https://doi.org/10.1016/S07323123(00)00028-6

Grover, B., \& Connor, J. (2000). Characteristics of the College Geometry Course for Preservice Secondary Teachers. Journal of Mathematics Teacher Education. https://doi.org/10.1023/A:1009921628065

Harisman, Y., Kusumah, Y. S., Kusnandi, K., \& Noto, M. S. (2019). the Teachers' Experience Background and Their Profesionalism. Infinity Journal, 8(2), 129-142. https://doi.org/10.22460/infinity.v8i2.p129-142

Kasoka, D., Jakobsen, A., \& Kazima, M. (2017). Preparing teachers for teaching: Does initial teacher education improve mathematical knowledge for teaching?. CERME 10,01949148

Korn, J. (2014). Teaching Conceptual Understanding of Mathematics via a Hands-On Approach. 1-29.

Mwakapenda, W. (2004). Understanding student understanding in mathematics. Pythagoras, (60), 28-35. https://doi.org/10.4102/pythagoras.v0i60.124

Philipp, R. A., Ambrose, R., Lamb, L. L. C., Sowder, J. T., Schappelle, B. P., Sowder, L., Thanheiser, E., \& Chauvot, J. (2007). Effects of early field experiences on the mathematical content knowledge and beliefs of prospective elementary school teachers: An experimental study. Journal for Research in Mathematics Education, $38(5), 438-476$.

Reid, M. (2013). Mathematics Content Knowledge, Mathematics Teacher Efficacy, and Pedagogy. University of Calgary. https://doi.org/10.11575/PRISM/26840 
Reid, M., \& Reid, S. (2017). Learning to be a math teacher: What knowledge is essential? International Electronic Journal of Elementary Education, 9(4), 851-872.

Sowder, J. T. (2007). The mathematical education and development of teachers. Second handbook of research on mathematics teaching and learning, 1, 157-223.

Stylianides, A. J., \& Stylianides, G. J. (2007). Learning mathematics with understanding: A critical consideration of the learning principle in the principles and standards for school mathematics. The Mathematics Enthusiast, 4(1), 103-114.

Thames, M., \& Ball, D. (2010). What math knowledge does teaching require? Teaching Children Mathematics, 17(4), 220-229.

Vistro-yu, C. P. (2013). Cross-national studies on the teaching and learning of mathematics : where do we go from here ?. ZDM, 45(1), 145-151. https://doi.org/10.1007/s11858013-0488-4 